\title{
Overexpression of Opa interacting protein 5 increases the progression of liver cancer via BMPR2/JUN/CHEK1/RAC1 dysregulation
}

\author{
YUWEN LI ${ }^{1,2}$, FEI XIAO ${ }^{3}$, WENTING LI $^{4}$, PINGPING HU ${ }^{5}$, RUIRUI XU ${ }^{5}$, \\ JUN LI ${ }^{5}$, GUIMEI LI ${ }^{1}$ and CHUANLONG ZHU ${ }^{5}$ \\ ${ }^{1}$ Department of Pediatrics, Shandong Provincial Hospital Affiliated to Shandong University, Jinan, Shandong 250021; \\ ${ }^{2}$ Department of Pediatrics, The First Affiliated Hospital of Nanjing Medical University, Nanjing, Jiangsu 210029; \\ ${ }^{3}$ Department of Infectious Diseases, The Fifth Affiliated Hospital of Sun Yat-sen University, Zhuhai, \\ Guangdong 519000; ${ }^{4}$ Third Liver Unit, Department of Infectious Disease, \\ The First Affiliated Hospital of Science and Technology of China, Hefei, Anhui 230001; \\ ${ }^{5}$ Department of Infectious Disease, The First Affiliated Hospital of Nanjing Medical University, \\ Nanjing, Jiangsu 210029, P.R. China
}

Received June 15, 2018; Accepted January 30, 2019

DOI: $10.3892 /$ or.2019.7006

\begin{abstract}
Opa interacting protein 5 (OIP5) overexpression is associated with human carcinoma. However, its biological function, underlying mechanism and clinical significance in liver cancer remain unknown. In the present study, the effects of OIP5 expression on liver cancer, and the mechanisms regulating these effects, were investigated. OIP5 expression was measured in human hepatocellular carcinoma (HCC) tissues and liver cancer cell lines. The effect of OIP5 knockdown on tumorigenesis was also detected in nude mice, and differentially-expressed genes (DEGs) were identified and their biological functions were identified. The results indicated that OIP5 expression was significantly upregulated in HCC tissues and four liver cancer cell lines $(\mathrm{P}<0.01)$. Increased OIP5 protein expression significantly predicted reduced survival rate of patients with HCC ( $\mathrm{P}<0.01)$. OIP5 knockdown resulted in the suppression of proliferation and colony forming abilities, cell cycle arrest at the G0/G1 or G2/M phases, and promotion of cell apoptosis. A total of 628 DEGs, including 87 upregulated and 541 downregulated genes, were
\end{abstract}

Correspondence to: Dr Guimei Li, Department of Pediatrics, Shandong Provincial Hospital Affiliated to Shandong University, 9677 Jingshi Road, Jinan, Shandong 250021, P.R. China E-mail: liguimei2013@126.com

Dr Chuanlong Zhu, Department of Infectious Disease, The First Affiliated Hospital of Nanjing Medical University, 300 Guangzhou Road, Nanjing, Jiangsu 210029, P.R. China

E-mail: chuanlong@yahoo.com

Key words: cell cycle, cell apoptosis, cell growth, liver cancer, Opa interacting protein 5 identified following OIP5 knockdown. Functional enrichment analysis indicated that DEGs were involved in 'RNA Post-Transcriptional Modification, Cancer and Organismal Injury and Abnormalities'. Finally, OIP5 knockdown in Huh7 cells dysregulated bone morphogenetic protein receptor type $2 / \mathrm{JUN} /$ checkpoint kinase $1 /$ Rac family small GTPase 1 expression. In conclusion, the overall results demonstrated the involvement of OIP5 in the progression of liver cancer and its mechanism of action.

\section{Introduction}

Liver cancer is the fifth most common cancer type in adult males and ninth in female worldwide in 2018; furthermore, liver cancer is the third leading cause of cancer-associated mortalities globally in 2018 (1), with $\sim 782,000$ deaths annually globally $(2,3)$. Frequent intrahepatic spread and extrahepatic metastasis are the primary factors of mortality during the initial diagnosis, and there is a $70 \% 5$-year recurrence rate of tumor recurrence (4). Patients with liver cancer are frequently diagnosed at an advanced stage of the disease and lose the possibility of an effective treatment with surgical resection and liver transplantation (5). Therefore, chemotherapy remains the only approach for treating patients with advanced liver cancer. Currently, the exact molecular mechanisms underlying liver cancer development remain unclear. Therefore, it is of utmost importance for the identification of reliable biomarkers for a precise prognosis, and development of more effective therapeutic approaches for individualized treatment of patients with liver cancer $(6,7)$.

Opa interacting protein 5 (OIP5) encodes a protein which appertain to cancer/testis antigens (CTAs) (8). The OIP5 gene localizes on chromosome 15 (8). OIP5 protein combined with C21orf45 and M18 binding protein 1 forms a complex, and then accumulates specifically at telophase-G1 centromeres, 
which is consequently essential for the structure and function of the centromere/kinetochore (9). This protein also regulates the cell cycle exit via interacting with the retinoblastoma protein through the E2F-Rb pathway (10).

Ectopic OIP5 expression is identified in a number of cancer types. For example, increased OIP5 expression is associated with advanced tumor stage and reduced patients overall survival time with clear cell renal cell carcinoma (11). OIP5 is also highly expressed in samples from patients with colorectal (12) and gastric cancer (13), and acute myeloid leukemia (14). Increased OIP5 expression is significantly associated with poor prognosis of patients with lung and esophageal cancer. Furthermore, it is also a potential target for the development of prognostic biomarkers and cancer therapy (15).

OIP5 upregulation induces AKT activation via mammalian target of rapamycin complex 2 (mTORC2) and p38/phosphatase and tensin homolog signaling pathways, and activates $\beta$-catenin signaling through enhancing its nuclear translocation by phosphorylating $\beta$-catenin and glycogen synthase kinase-3 $\beta$ (16). Additionally, OIP5 downregulation inhibits OIP5 oncogenic signaling through its action on mTORC1 and $\beta$-catenin pathways (16). OIP5 expression is significantly increased in GIII/IV (Edmondson grade) hepatocellular carcinoma (HCC), compared with in GI/II HCC, through the analysis of GSE36411 dataset derived from the Gene Expression Omnibus database (16).

Until now, despite all these studies aforementioned, no report is available concerning OIP5 expression status and biological functions in human liver cancer, as well as the precise OIP5 mechanism in liver cancer. Therefore, OIP5 protein expression in HCC specimens was detected in the present study. The association between its expression and clinicopathological characteristics in patients with HCC was also investigated. The results demonstrated that OIP5 downregulation influenced cell proliferation, apoptosis, colony formation and the cell cycle in liver cancer cell lines, as well as cell signaling in Huh7 cells. These data may provide beneficial information regarding liver cancer pathogenesis, and reveal a potential biomarker for liver cancer therapy.

\section{Materials and methods}

Patients and tissue specimens. From September 2007 to March 2008, a total of 75 Chinese Han patients with recently diagnosed primary HCC and who had received surgical resection of HCC neoplasm were recruited by the First Affiliated Hospital of Nanjing Medical University (Nanjing, China). The ages of the patients at diagnosis ranged from 34-63 years, with a median age of 46 years. The clinical diagnosis of HCC was based on the National Comprehensive Cancer Network clinical practice guidelines in oncology and histopathological examination (3). Liver samples were specimens classified as a carcinoma or para-carcinoma. Subsequently, clinical samples were fixed in $4 \%$ formalin overnight, dehydrated in graded ethanol (70, 80, 90, 95 and 100\%) and paraffin-embedded at room temperature. Following this, $5 \mu \mathrm{m}$-thick sections were obtained using a Microm HM 355S microtome, and then mounted on Superfrost Plus slides (both from Thermo Fisher Scientific, Inc., Waltham, MA, USA). Hematoxylin and eosin staining was performed according to the protocol of the
Department of Pathology at the First Affiliated Hospital of Nanjing Medical University (17). HCC and non-tumor tissues histologically were confirmed by two pathologists who were blind to the patients' information. Data for the age at diagnosis, sex, tumor size, pathological grade and tumor-node-metastasis (TNM) stage were obtained and listed in Table I $(18,19)$.

The present study was performed according to the World Medical Association Declaration of Helsinki on ethical principles for medical research involving human subjects. All research procedures were approved by the Research Ethics Committee of the First Affiliated Hospital of Nanjing Medical University. All research subjects provided signed written informed consent. The clinical outcomes of HCC were recorded until April 2018.

Immunohistochemical (IHC) staining. Tissue sections $(5-\mu \mathrm{m})$ were heated at $60^{\circ} \mathrm{C}$, deparaffinized, and hydrated by successive washes in xylene 3 times, graded by 100, 95 and $70 \%$ ethanol, and then PBS. OIP5 antigen was recovered through incubation with $0.1 \mathrm{~mol} / 1$ citrate buffer $(\mathrm{pH} 6.0$; Abcam, Cambridge, UK) for $30 \mathrm{~min}$ at $95^{\circ} \mathrm{C}$. Slides were then washed with PBS three times and incubated at room temperature with $3 \%(\mathrm{v} / \mathrm{v}) \mathrm{H}_{2} \mathrm{O}_{2}$ for $10 \mathrm{~min}$ to quench endogenous peroxidase activity. Following an additional three washes with PBS, the slides were blocked against non-specific epitopes via incubation with PBS containing $10 \%$ (w/v) normal goat serum and $1 \%(\mathrm{w} / \mathrm{v})$ bovine serum albumin (Abcam) for $30 \mathrm{~min}$ at room temperature. Slides were subsequently incubated overnight at $4^{\circ} \mathrm{C}$ with mouse anti-human OIP5 monoclonal antibody (1:1,000 dilution; Sigma-Aldrich; Merck KGaA, Darmstadt, Germany; cat no. SAB1407138), and washed with PBS three times. Slides were labeled with a biotinylated goat anti-mouse secondary antibody (ready for use; OriGene Technologies, Inc., Beijing, China; cat no. SP9002) for $30 \mathrm{~min}$ at room temperature, and washed with PBS three times. Subsequently, slides were incubated with horseradish peroxidase-labeled streptavidin (ready for use; OriGene Technologies, Inc.; cat no. SP9002) for $30 \mathrm{~min}$ at room temperature, and washed with PBS three times. Finally, the enzymatic reaction was triggered using 3,3'-diaminobenzidine (Sangon Biotech Co., Ltd., Shanghai, China) for $5 \mathrm{~min}$. Slides were counter stained with hematoxylin (Sigma-Aldrich; Merck KGaA) for $30 \mathrm{sec}$ at room temperature and washed with PBS for $5 \mathrm{~min}$, and then examined under an optical microscope (magnification, $x 400$ ). Using Image Pro-Plus v6.0 (Media Cybernetics Corporation, Arrendale, PA, USA) and the following formula: IHC staining score $=$ intensity score $\mathrm{x}$ positive rate score, IHC staining area of each slide was analyzed and quantified. Intensity score was scored as follows: 0 (negative), 1 (weakly positive), 2 (moderately positive) and 3 (strongly positive). Positive rate score was scored as follows: Negative, 1-25; 26-50; 51-75; and 76-100\%, which represented $0,1,2,3$ and 4 , respectively. Finally, slides with an IHC staining score of 0-5 and 6-12 were defined as OIP5 low and high expression, respectively.

In order to analyze OIP5 mRNA differential expression in liver cancer and paired liver tissues, the online database Gene Expression Profiling Interactive Analysis (GEPIA; http:/gepia.cancer-pku.cn/index.html) was used. Additionally, in order to deduce the association between OIP5 mRNA differential expression in liver cancer and normal liver 
Table I. Association between OIP5 expression and clinicopathological parameters of patients with liver cancer.

\begin{tabular}{|c|c|c|c|c|c|}
\hline \multirow[b]{2}{*}{ Variable } & \multirow[b]{2}{*}{ Cases (n) } & \multicolumn{2}{|c|}{ OIP5 expression levels } & \multirow[b]{2}{*}{$\chi^{2}$} & \multirow[b]{2}{*}{ P-value } \\
\hline & & Low & High & & \\
\hline \multicolumn{6}{|c|}{ Age (years) } \\
\hline$<60$ & 57 & 41 & 16 & 0.753 & 0.386 \\
\hline$\geq 60$ & 18 & 11 & 7 & & \\
\hline \multicolumn{6}{|l|}{ Sex } \\
\hline Male & 62 & 41 & 21 & 0.967 & 0.325 \\
\hline Female & 13 & 11 & 2 & & \\
\hline \multicolumn{6}{|c|}{ Tumor size (cm) } \\
\hline$<3$ & 18 & 15 & 3 & 0.671 & 0.413 \\
\hline$\geq 3$ & 57 & 37 & 20 & & \\
\hline \multicolumn{6}{|c|}{ Pathological grade (18) } \\
\hline I-II & 69 & 49 & 20 & 0.371 & 0.542 \\
\hline III & 6 & 3 & 3 & & \\
\hline \multicolumn{6}{|c|}{ TNM stage (19) } \\
\hline I-II & 45 & 33 & 12 & 0.847 & 0.358 \\
\hline III-IV & 30 & 19 & 11 & & \\
\hline
\end{tabular}

TNM, tumor-node-metastasis ; OIP5, Opa interacting protein 5.

tissues, and to produce an overall survival rate curve, the online database Kaplan-Meier Plotter (http://kmplot.com/ analysis/index.php?p=service\&cancer=liver_rnaseq) (20) was also employed.

Cell culture. Human liver cancer cell lines HepG2, Hep3B, Huh7, human embryonic kidney (HEK) 293T cells and primary human hepatocyte $(\mathrm{PHH})$ cells were purchased from the Shanghai Cell Bank of Chinese Academy of Science (Shanghai, China). Cell lines were cultured in Dulbecco's modified Eagle's medium (DMEM) supplemented with $10 \%$ fetal bovine serum (FBS) $1 \%$ penicillin and streptomycin solution (all from Gibco; Thermo Fisher Scientific, Inc.), and incubated at $37^{\circ} \mathrm{C}$ in a $5 \% \mathrm{CO}_{2}$ humidified atmosphere. All experiments were executed using cells at a confluence $>75 \%$. HepG2, Hep3B, Huh7 and PHH cells were harvested and used for reverse transcription-quantitative polymerase chain reaction (RT-qPCR) and western blot analysis. 293T cells were used as packaging host for production of lentiviruses. HepG2 and Huh7 cells were used for an MTT assay, colony formation assay, apoptosis assay and microarray analysis after being transfected with pGCSIL-shOIP5 or pGCSIL-shCtrl lentivirus.

Lentiviral short hairpin RNA (shRNA) vector construction and cell transfection. OIP5 knockdown was performed using shRNA against human OIP5 gene (GenBank accession no. NM_007280) designed from the full-length OIP5 sequence and synthesized by Shanghai GeneChem Co., Ltd. (Shanghai, China). The OIP5 gene shRNA sequence was as follows: 5'-CTACCTCTGAAGGCTACACTT-3', while the scramble sequence was the following: 5'-TTCTCCGAA CGTGTCACGT-3'. Knockdown efficiency was tested using stem-loop oligonucleotides synthesized and inserted into a pGCSIL-GFP vector (Shanghai GeneChem Co., Ltd.), which was termed pGCSIL-shOIP5. pGCSIL-GFP was used as negative-control and was termed pGCSIL-shCtrl. Lentivirus particles were packaged as previously described (21). Briefly, the lentiviral particles were produced by co-transfection of pGCSIL-shOIP5/pGCSIL-shCtrl into 293T cells using a pHelper system (Shanghai GeneChem Co., Ltd.), according to the manufacturer's protocols. Lipofectamine ${ }^{\circledR} 2000$ (Invitrogen; Thermo Fisher Scientific, Inc.; cat. no. 11668019) was used according to the manufacturers protocols to transfect $1 \mu \mathrm{g} /$ well plasmid into the cells. Lentiviruses were harvested at $48 \mathrm{~h}$ post-transfection.

Huh7 and HepG2 cells $\left(5 \times 10^{4}\right.$ cells/well) were seeded into 6 -well plates and transfected with pGCSIL-shOIP5 lentivirus or pGCSIL-shCtrl at a multiplicity of infection of 20 , according to the aforementioned protocol. Cells were incubated in a $5 \% \mathrm{CO}_{2}$ humidified incubator at $37^{\circ} \mathrm{C}$. After $72 \mathrm{~h}$, cells were observed under a fluorescence microscope (MicroPublisher ${ }^{\mathrm{TM}}$ 3.3RTV; Olympus Corporation, Tokyo, Japan) to evaluate their health status. After 5 days, knockdown efficiency was examined using western blotting and RT-qPCR as subsequently described.

$R T-q P C R$. Total RNA was separated from dissected tumor and non-tumor tissues, and three cell lines, using the TRIzol ${ }^{\circledR}$ reagent (Sangon Biotech Co., Ltd.), based on the manufacturer's protocols. RT was executed using $2 \mu \mathrm{g}$ total RNA, $1 \mu \mathrm{l}$ (200 units) RT-PCR SuperScript II (Invitrogen; Thermo Fisher Scientific, Inc.) and $50 \mu \mathrm{M}$ decamer at $37^{\circ} \mathrm{C}$ for $50 \mathrm{~min}$. Specific primers targeting OIP5 were designed by Shanghai GeneChem Co., Ltd. as follows: 5'-TGGCATTGAAGGTTC 
ACTCA-3' (forward) and 5'-AGGGCAGCATGGGTAGAA TA-3' (reverse), with a product length of $189 \mathrm{bp}$. RT-qPCR was performed by SYBR ${ }^{\circledR}$ Master Mix Kit (Takara Biotechnology Co., Ltd., Dalian, China) on a Mx3000P qPCR system (Agilent Technologies, Inc., Santa Clara, CA, USA) and LightCycler 480 (Roche Diagnostics, Indianapolis, IN, USA). The housekeeping gene GAPDH was used for normalization. Data were calculated using the Pfaffl method (22). PCR primers used for validating the microarray data are listed in Table II. The thermal profile conditions were $30 \mathrm{sec}$ at $95^{\circ} \mathrm{C}$, $30 \mathrm{sec}$ at $62^{\circ} \mathrm{C}$ and $30 \mathrm{sec}$ at $72^{\circ} \mathrm{C}$ for 40 cycles, and a final extension at $72^{\circ} \mathrm{C}$ for $5 \mathrm{~min}$.

Western blot analysis. For western blot analysis, cells $\left(5 \times 10^{4} /\right.$ well) were seeded in 6-well culture plates and incubated in a $\mathrm{CO}_{2}$ incubator at $37^{\circ} \mathrm{C}$ until they reached $30 \%$ confluence. Subsequently, cells were transfected with pGCSIL-shOIP5 lentivirus or pGCSIL-shCtrl lentivirus, according to the aforementioned protocol, and continuously incubated for 120 h. Subsequently, cells were lysed using ice-cold lysis buffer (100 mM Tris, pH $6.82 \%$ b-mercaptoethanol, 20\% glycerol and 4\% SDS). The lysates were centrifuged for $10 \mathrm{~min}$ at $12,000 \mathrm{xg}$ and $4^{\circ} \mathrm{C}$, and then the supernatants were collected and the protein concentration was determined using a Bicinchoninic Acid Protein Assay kit (Pierce; Thermo Fisher Scientific, Inc.). According to Laemmli's method (23), equal amounts $(20 \mu \mathrm{g})$ of proteins from each sample were separated by $10 \%$ SDS-PAGE, and transferred to polyvinylidene difluoride membranes (Bio-Rad Laboratories, Inc., Hercules, CA, USA). Membranes were incubated in 5\% skimmed milk diluted by TBST ( $25 \mathrm{mM}$ Tris, pH 7.4, 0.1\% Tween-20, $150 \mathrm{mM} \mathrm{NaCl}$ ) for $1 \mathrm{~h}$ at room temperature. Subsequently, membranes were incubated overnight at $4^{\circ} \mathrm{C}$ with the following primary antibodies: Rabbit polyclonal anti-OIP5 (ProteinTech Group, Inc. Chicago, IL, USA; cat no. 12142-1-AP; 1:500 dilution), mouse monoclonal anti-Flag M2 (Sigma-Aldrich; Merck KGaA; cat no. F1804; 1:1,000 dilution), mouse polyclonal anti-bone morphogenetic protein receptor type 2 (BMPR2; Abcam; cat no. ab130206; 1:200 dilution), rabbit monoclonal anti-JUN (Abcam; cat no. ab32137; 1:1,000 dilution), rabbit anti-cullin 4B (Abcam; cat no. ab85610; 1:1,000 dilution), mouse monoclonal anti-checkpoint kinase 1 (CHEK1; Cell Signaling Technology, Inc., Danvers, MA, USA; cat no. \#2360S; 1:1,000 dilution), rabbit polyclonal anti-Rac family small GTPase 1 (RAC1; Abcam; cat no. ab97568; 1:500 dilution), rabbit monoclonal anti-baculoviral IAP repeat containing 3 (Abcam; cat no. ab32059; 1:1,000 dilution) or mouse monoclonal anti-GAPDH (Santa Cruz Biotechnology, Inc., Dallas, TX, USA; cat no. sc-32233; 1:2,000 dilution). Finally, goat anti-mouse (Santa Cruz Biotechnology, Inc.; cat no. sc-2005; 1:5,000 dilution) or goat anti-rabbit horseradish peroxidase (Santa Cruz Biotechnology, Inc.; cat no. sc-2004; 1:5,000 dilution) secondary antibodies were used for $1 \mathrm{~h}$ at $37^{\circ} \mathrm{C}$. Signals were detected using an Enhanced Chemiluminescent-PLUS/kit (GE Healthcare Life Sciences, Little Chalfont, UK; cat no. RPN2132), according to the manufacturer's protocols. GAPDH was used as internal control.

MTT assay. Proliferation of HepG2 and Huh7 cells transfected with pGCSIL-shOIP5 or pGCSIL-shCtrl plasmid was determined using an MTT assay. Transfected HepG2 and Huh7 cells $(1,000$ cells $/ 100 \mu 1 /$ well $)$ within the logarithmic phase were seeded in 96 -well culture plates and incubated at $37^{\circ} \mathrm{C}$ in an atmosphere containing $5 \% \mathrm{CO}_{2}$ for 5 days. Subsequently, $10 \mu 1$ MTT $(5 \mathrm{mg} / \mathrm{ml}$; Beijing Dingguo Changsheng Biotechnology Co., Ltd., Beijing, China) was added to each well, and incubated at $37^{\circ} \mathrm{C}$ for $4 \mathrm{~h}$ at the end of the incubation time. Afterwards, the supernatant was discarded, and $100 \mu \mathrm{l}$ dimethyl sulfoxide (Sinopharm Chemical Reagent Co., Ltd., Shanghai, China) were added to each well, and incubated at $37^{\circ} \mathrm{C}$ for $10 \mathrm{~min}$ in an air bath shaker. The absorbance was measured at $490 \mathrm{~nm}$ using an ELx800 microplate reader (BioTek Instruments, Inc., Winooski, VT, USA).

Colony formation assay. The effect of OIP5 knockdown on colony formation following pGCSIL-shOIP5 transfection was determined in parallel with the effect following transfection with pGCSIL-shCtrl. Transfected Huh7 and HepG2 cells $(1,000$ cells/well $)$ were seeded in a 6 -well culture plates and incubated at $37^{\circ} \mathrm{C}$ for 10 days to form colonies. DMEM was replaced every 2 days with fresh DMEM containing 10\% FBS and $1 \%$ penicillin-streptomycin. Cells were washed with PBS three times (pH 7.2) and fixed with $4 \%$ paraformaldehyde (Sangon Biotech Co., Ltd.) at room temperature for $30 \mathrm{~min}$. The fixed cells were washed with PBS three times and stained with $100 \mu \mathrm{l}$ Giemsa staining solution (Chemicon International; Thermo Fisher Scientific, Inc.) at room temperature for $20 \mathrm{~min}$. The total number of colonies containing $>50$ cells was calculated under an optical microscope (magnification, $\mathrm{x} 400$ ).

Cell cycle and apoptosis analysis. The proportion of cells at each cell cycle stage or undergoing apoptosis was inspected by flow cytometry (FCM) following OIP5 knockdown. After 4 days post-lentiviral infection, HepG2 and Huh7 cells were seeded in 6-cm dishes ( $1 \times 10^{6}$ cells/dish). Cells were harvested when the coverage rate of cells was $>70 \%$, and subsequently fixed with $70 \%$ ice ethanol for $1 \mathrm{~h}$ at $4^{\circ} \mathrm{C}$. Cells were then washed with PBS three times (pH 7.2), treated with $1.5 \mathrm{ml}$ PBS containing $50 \mu \mathrm{g} / \mathrm{ml}$ propidium iodide (Sigma-Aldrich; Merck KGaA; cat no. P4170) and $100 \mu \mathrm{g} / \mathrm{ml}$ RNase A (Fermentas; Thermo Fisher Scientific, Inc.; cat no. EN0531), and incubated in the dark at room temperature for $30 \mathrm{~min}$. The suspension was filtered using a 300-mesh and then subjected to FCM with a FACS Calibur flow cytometer (BD Biosciences; Becton Dickinson and Company, Franklin Lakes, NJ, USA) to determine cell cycle phases. The data were analyzed by WinMDI v2.9 software (The Scripps Research Institute, San Diego, CA, USA). All experiments were executed in triplicate. To identify cells undergoing apoptosis, Huh7 and HepG2 cells were cultured with DMEM containing $10 \%$ FBS and $1 \%$ penicillin-streptomycinin6-well culture plates $\left(5 \times 10^{4}\right.$ cells $/ 4 \mathrm{ml} /$ well $)$ at $37^{\circ} \mathrm{C}$. After 5 days post-lentiviral infection, transfected cell lines were collected and washed with ice-cold PBS three times ( $\mathrm{pH}$ 7.4). Subsequently, cell concentrations were adjusted to $1 \times 10^{6}$ cells $/ \mathrm{ml}$ using $1 \mathrm{X}$ binding buffer (eBioscience; Thermo Fisher Scientific, Inc.; cat no. 88-8007). Cell suspension $(100 \mu \mathrm{l})$ were stained with $5 \mu \mathrm{l}$ Annexin V-APC (eBioscience; Thermo Fisher Scientific, Inc.; cat no. 88-8007) and incubated in the dark for 10-15 min at room temperature. Cells were analyzed by FCM with a 
Table II. Primer sequences used for reverse transcription-quantitative polymerase chain reaction.

\begin{tabular}{|c|c|c|}
\hline Gene & Primer sequence 5'-3' & Fragment length (bp) \\
\hline RPS6KB1 FP & TGTTGCTTCTGAATCACTGTTG & 154 \\
\hline RPS6KB1 RP & GTCTTTGCTTCCATTTTGCTG & \\
\hline BMPR2 FP & ACGGGTATCTTTTGTTGGTGT & 213 \\
\hline BMPR2 RP & TGTCAGCTTTCATAGTGGCATC & \\
\hline CHEK1 FP & ACCTGCTTTACATTTCCACTTG & 174 \\
\hline CHEK1 RP & ACAGCAAACAGAGGAGGTTATT & \\
\hline CUL4B FP & TCTAACTCATCCCTGATGGTCT & 234 \\
\hline CUL4B RP & TTAAACAGCTCCССТCAACTT & \\
\hline JUN FP & ATGGTCAGGTTATACTCCTCCTC & 164 \\
\hline JUN RP & CACATGCCACTTGATACAATCC & \\
\hline RAC1 FP & GTAGCAGCTCAGCTCTTTGGA & 228 \\
\hline RAC1 RP & TACCCGTGACACTTTCATTCC & \\
\hline HNRNPU FP & TACCAAATAAGCAACAGGGAG & 249 \\
\hline HNRNPU RP & AAGCCAGTTTACACTCAGCAT & \\
\hline MAD2L1 FP & TTCTTCTCATTCGGCATCAAC & 229 \\
\hline MAD2L1 RP & TTTCCAGGACCTCACCACTTT & \\
\hline EEF1A1 FP & GGGATGGAAAGTCACCCGTAA & 104 \\
\hline EEF1A1 RP & GCAAGGGCTTGTCAGTTGGAC & \\
\hline PDIA3 FP & ATTTCGTCCTTCACATCTCAC & 243 \\
\hline PDIA3 RP & ACCATCATTACCCTGTTTCTC & \\
\hline GAPDH FP & TGACTTCAACAGCGACACCCA & 121 \\
\hline GAPDH RP & CACCCTGTTGCTGTAGCCAAA & \\
\hline
\end{tabular}

FP, forward primer; RP, reverse primer; RPS6KB1, ribosomal protein S6 kinase B1; BMPR2, bone morphogenetic protein receptor type 2; CHEK1, checkpoint kinase 1; CUL4B, cullin 4B; RAC1, Rac family small GTPase 1; HNRNPU, heterogeneous nuclear ribonucleoprotein U; MAD2L1, mitotic arrest deficient 2 like 1; EEF1A1, eukaryotic translation elongation factor 1 $\alpha 1$; PDIA3, protein disulfide isomerase family A member 3 .

flow cytometer within $1 \mathrm{~h}$. All experiments were executed in triplicate.

RNA isolation and microarray analysis. The expression status of 20,000 genes was determined in Huh7 cells transfected with pGCSIL-shOIP5 or pGCSIL-shCtrl lentiviruses. Initially, RNA was isolated from Huh-7 cells $72 \mathrm{~h}$ post transfection using TRIzol ${ }^{\circledR}$ reagent (Invitrogen; Thermo Fisher Scientific, Inc.), and the RNA quality was evaluated using a NanoDrop 2000 spectrophotometer and Agilent Bioanalyzer 2100. Individual microarrays of gene expression profiles (GeneChipPrimeview Human Gene Expression Array; cat no. 901838; Affymetrix; Thermo Fisher Scientific, Inc.) were used for each sample of the transfected cells aforementioned. Concisely, $0.5 \mu \mathrm{g}$ RNA were used to synthesize cDNA. Reverse transcription was performed using a High Capacity RNA-to-cDNA kit (Applied Biosystems; Thermo Fisher Scientific, Inc.). Biotin-labeled amplified RNA was synthesized from a double-stranded cDNA using the GeneChip 3' IVT labeling kit (Affymetrix; Thermo Fisher Scientific, Inc.). The wash and staining protocols were performed using a GeneChip Hybridization Wash and Stain kit and GeneChip Fluidics Station 450 (both from Affymetrix; Thermo Fisher Scientific,
Inc.), respectively, according to the manufacturer's protocols. Finally, the probe arrays were scanned using a GeneChip Scanner 3000 (Affymetrix; Thermo Fisher Scientific, Inc.).

Microarray data normalization and analysis. GeneSpring v11 software (Agilent Technologies, Inc.) was used to analyze microarray data. Initially, data associated withpGCSIL-shOIP5- and pGCSIL-shCtrl-transfected cells were normalized using GeneSpring normalization algorithms. Genes differentially expressed by at least \pm 1.5 -fold were determined as statistically significant $(\mathrm{P}<0.05)$, according to the Student's t-test based on the normalized data, relative to the negative control. A series of transcripts that were differentially expressed as a function of the transfection was produced, and they were hierarchically clustered based on certain associations. Enriched pathways were determined using Kyoto Encyclopedia of Genes and Genomes (KEGG; https://www. genome.jp/kegg/) and Ingenuity Pathway Analysis (IPA; http://www.qiagen.com/ingenuity). Finally, gene sets with significantly different expression levels were used to identify molecular functions by RT-qPCR and western blotting, as aforementioned. The primers used to perform RT-qPCR are listed in Table II. 
Tumorigenesis in nude mice. A total number of 20 female BALB/c nude mice, 4-week old, weighing $20 \pm 2 \mathrm{~g}$ were purchased at Shanghai GeneChem Co., Ltd. Mice were kept in a pathogen-free animal facility at a 12:12-h light-dark cycle at a constant temperature of $23 \pm 1^{\circ} \mathrm{C}$ and humidity of $50 \pm 1 \%$, fed with a standard diet. All mice were bred according to the experimental animal care and research protocol, which was approved by the Ethics Committee of the Institutional Review Board of the Nanjing Medical University on Animal Experiments (Nanjing, China). Tumorigenesis in nude mice was determined as previously described (24). Briefly, Huh7 cells successfully transfected with pGCSIL-shOIP5 or pGCSIL-pGCSIL-shCtrl lentivirus were subcutaneously injected into the mice abdomen at a single site. The tumor size was determined using a caliper of the excised neoplasm at the time of execution. The animals were sacrificed by cervical dislocation at 4 weeks after injection. All experiments on mice were performed in accordance with the Guide for the Care and Use of Laboratory Animals (25) and approved by the Ethics Committee of the Institutional Review Board of the Nanjing Medical University on Animal Experiments.

Statistical analyses. Data were analyzed by SPSS v16 (SPSS, Inc., Chicago, IL, USA). All categorical data are indicated as a frequency. The associations between OIP5 expression in the human samples and clinical variables were analyzed using the $\chi^{2}$ test. The association between OIP5 expression in tumors and patient disease-specific survival rate was fitted with Kaplan-Meier survival curves and assessed with the log-rank test. A Cox proportional hazards model was fitted for multivariable analysis. Quantitative data are presented as the mean \pm standard deviation. Statistical analyses were performed using unpaired Student's t-test and one-way analysis of variance followed by Dunnett's tests. $\mathrm{P}<0.05$ was considered to indicate a statistically significant difference.

\section{Results}

OIP5 expression in tumor and non-tumor adjacent tissue. Firstly, the online database GEPIA was used to investigate OIP5 mRNA differential expression between liver cancer and normal liver tissues. GEPIA data analysis indicated that OIP5 mRNA expression was significantly increased in liver cancer tissues, compared with normal liver tissues $(\mathrm{P}<0.05$; Fig. 1A). To verify these results, OIP5 expression in liver tissue was evaluated through IHC staining. As depicted in Fig. 1B, OIP5 staining was brown, particularly in the tumor cytoplasm. The positive rate of OIP5 expression in carcinoma tissues was notably increased, compared with non-cancerous tissue. Subsequently, the characteristics of patients recruited, including age, sex, tumor size, pathological grading and TNM stage, were summarized and analyzed. As depicted in Table I, there was no significant difference in OIP5 expression between early and late stage HCC. Finally, the online tool Kaplan-Meier plotter was used to analyze the association between OIP5 expression and the prognosis of patients. It was observed that the survival rate of patients with high OIP5 expression was significantly reduced, compared with those with low OIP5 expression $(\mathrm{P}<0.01$, Fig. $1 \mathrm{C})$.
OIP5 endogenous expression in liver cancer cell lines and PHH cells. As depicted in Fig. 2, endogenous OIP5 expression was significantly increased in Huh7 and HepG2 cell lines, compared with PHH cells $(\mathrm{P}<0.01)$. Western blotting confirmed OIP5 protein expression in those cells. These data indicated that OIP5 is highly expressed in liver cancer cell lines.

Effect of pGCSIL-shOIP5 lentivirus transfection on OIP5 expression in Huh7 and HepG2 cell lines. Huh7 and HepG2 cell lines were infected with lentivirus-pGCSIL-shOIP5 and lentivirus-pGCSIL-shCtrl. As depicted in Fig. 3A, Huh7 and HepG2 cells were successfully transfected with pGCSIL-shOIP5/pGCSIL-shCtrl lentivirus. To investigate the knockdown effect of the pGCSIL-shOIP5 lentivirus, OIP5 expression in the Huh7 and HepG2 cell lines were quantified by RT-qPCR and western blot analysis. OIP5 mRNA expression was significantly decreased by pGCSIL-shOIP5 lentivirus transfection in Huh7 and HepG2 cell lines, compared with pGCSIL-shCtrl lentivirus transfection $(\mathrm{P}<0.01$; Fig. 3B). As depicted in Fig. 3C, OIP5 protein expression was also inhibited by pGCSIL-shOIP5 lentivirus transfection in Huh7 and HepG2 cell lines, which identified that the GCSIL-shOIP5 lentivirus could effectively silence the target gene.

Effect of OIP5 knockdown in liver cancer cell lines on cell proliferation. As depicted in Fig. 4A, and determined by quantification in Fig. 4B, the number of Huh7 cells transfected with pGCSIL-shCtrl lentivirus significantly increased over the 5 days of observation, while the number of pGCSIL-shOIP5-transfected Huh7 cells remained almost the same. The proliferation activity was examined using an MTT assay and expressed as optical density $490 \mathrm{~nm}$. As depicted in Fig. 4C, the proliferative effect of Huh7 cells transfected with pGCSIL-shCtrl was increased, compared with Huh7 cells transfected with pGCSIL-shOIP5 $(\mathrm{P}<0.01)$. Additionally, the results were further confirmed in HepG2 cells (Fig. 4D-F). These data indicated that the proliferation of Huh7 or HepG2 cells could be significantly suppressed by OIP5 knockdown.

Effect of OIP5 knockdown on colony formation. Impairment of colony formation between pGCSIL-shOIP5-transfected Huh7 cells and pGCSIL-shCtrl-transfected Huh7 cells was observed, as depicted in Fig. 5A. Furthermore, when counted, OIP5-knockdown Huh7 cells colony numbers were significantly reduced, compared with the number in the controls with functional OIP5 ( $\mathrm{P}<0.01$; Fig. 5B). Similarly, OIP5 knockdown significantly affected the colony formation of HepG2 cells $(\mathrm{P}<0.01$; Fig. $5 \mathrm{C}$ and $\mathrm{D})$. These data indicated that silencing of OIP5 expression could inhibit colony forming in liver cancer cells.

Effect of OIP5 knockdown in liver cancer cells on the cell cycle. OIP5 knockdown significantly decreased the number of cells in the $\mathrm{S}$ phase, and significantly increased the number of cells in the $G_{0} / G_{1}$ phases in HepG2 and Huh7 cells $(P<0.05$, Fig. 6). These results indicated that those cells were arrested following OIP5 gene knockdown and OIP5 was strongly associated with cell cycle distribution. 

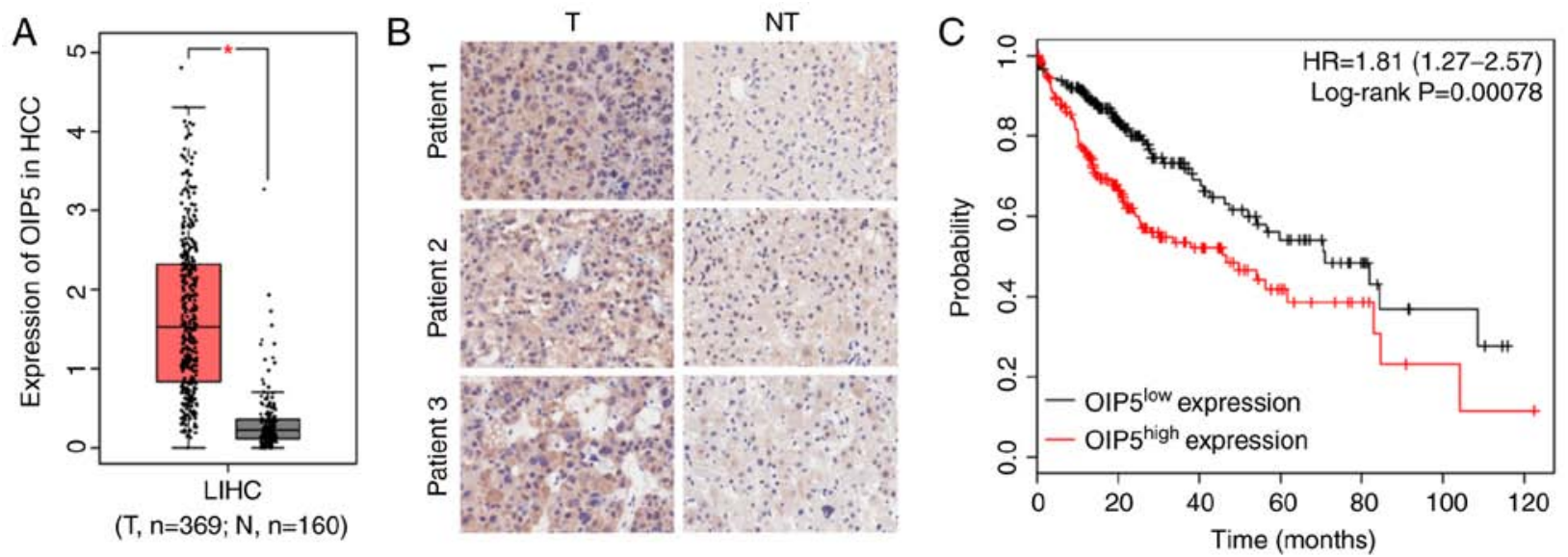

Figure 1. Protein expression of OIP5 in HCC tissues and non-tumor adjacent tissues and overall survival curves analysis. (A) OIP5 mRNA overexpression in liver cancer predicted by Gene Expression Profiling Interactive Analysis. (B) Representative pictures of immunohistochemistry analysis of OIP5 protein in primary HCC T and NT tissues (magnification, x400). (C) The association between overall survival time and differential OIP5 expression in HCC was analyzed by a Kaplan-Meier survival curve. "P<0.05. T, tumor; NT, non-cancerous; OIP5, Opa interacting protein 5; HR, hazard ratio; N, non-tumor; HCC, hepatocellular carcinoma; LIHC, liver hepatocellular carcinoma.

A

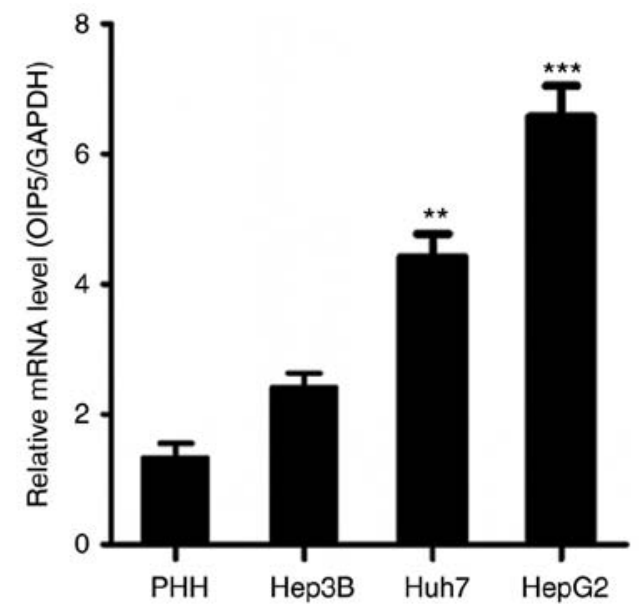

B

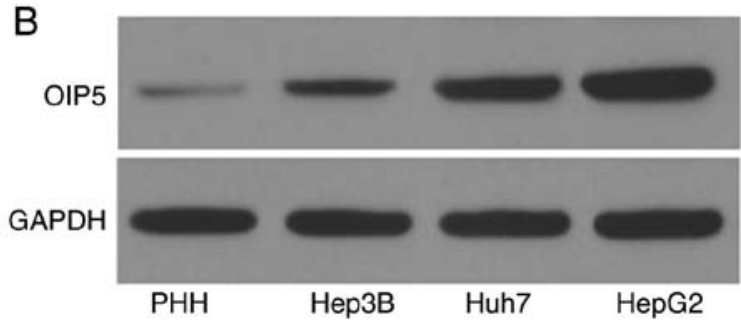

Figure 2. OIP5 endogenous expression in liver cancer cell lines and $\mathrm{PHH}$. (A) Endogenous OIP5 mRNA expression in Hep3B, Huh7, HepG2 and PHH cells analyzed by reverse transcription-quantitative polymerase chain reaction. GAPDH was used as an internal control for normalization. ${ }^{* * *} \mathrm{P}<0.01$ and ${ }^{* * *} \mathrm{P}<0.001$ vs. the PHH group. (B) OIP5 protein expression in four liver cancer cell lines and PHH cells by western blotting analysis. GAPDH was used as an internal control. PHH, primary human hepatocyte; OIP5, Opa interacting protein 5 .

Effect of OIP5 knockdown in liver cancer cells on apoptosis. As depicted in Fig. 7, cell apoptosis was significantly increased in cells following OIP5 knockdown, compared with the control cells with OIP5 intact expression $(\mathrm{P}<0.05)$. These data indicated that silencing OIP5 promoted the apoptosis of liver cancer cells, including HepG2 and Huh7 cells.
Effect of OIP5 knockdown in Huh7 cells on gene expression. A total of 20,000 genes were analyzed by microarray to determine the influence of OIP5 knockdown on downstream gene expression. A total number of 628 genes were differentially expressed in OIP5 knockdown Huh7 cells, compared with control Huh7 cells $( \pm 2.0$-fold change; $\mathrm{P}<0.05), 87$ of which were upregulated, whilst the remaining 541 were downregulated. Hierarchical clustering of the microarray data was depicted in Fig. 8A. Biological interactions were identified in the 628 DEGs using IPA and KEGG pathway analysis. Of these networks, a list of the top 10 networks was depicted in Fig. 8B, and those genes associated with 'RNA Post-Transcriptional Modification, Cancer, Organismal Injury and Abnormalities' were part of the highest ranked network. Fig. $8 \mathrm{C}$ depicts that OIP5 is located upstream of all focus genes.

Effect of OIP5 knockdown in Huh7 cells on $B M P R 2 / J U N / C H E K 1 / R A C 1$. To understand the molecular mechanisms underlying OIP5-mediated cancer growth, apoptotic genes mRNA expression was evaluated in liver cancer cells following OIP5 knockdown. As depicted in Fig. 9A, OIP5 may affect the growth or apoptosis of Huh7 cells through the microRNA-1/heterogeneous nuclear ribonucleoprotein U(HNRNPU) and cyclindependentkinaseinhibitor2A/eukaryotic translation elongation factor $1 \alpha 1$ (EEF1A1)/mitotic arrest deficient 2 like 1 (MAD2L1) pathways. RT-qPCR analyses were further performed to evaluate downstream gene expression, and it was determined that JUN,RAC1, MAD2L1, HNRNPU and EEF1A1 mRNA expression was significantly decreased following OIP5 knockdown, while BMPR2 and CHEK1 were significantly upregulated. Furthermore, it was identified via western blotting that OIP5 knockdown markedly altered the expression of proteins, including as JUN, RAC1, BMPR 2 and CHEK1 (Fig. 9B and C). Collectively, these results indicated that OIP5 was involved in the growth and apoptosis of liver cancer cells via dysregulation of RAC1/JUN/BMPR2/CHEK1.

OIP5 knockdown inhibits tumorigenicity of HCC in vivo. To examine the effects of OIP5 knockdown on tumor growth 
A
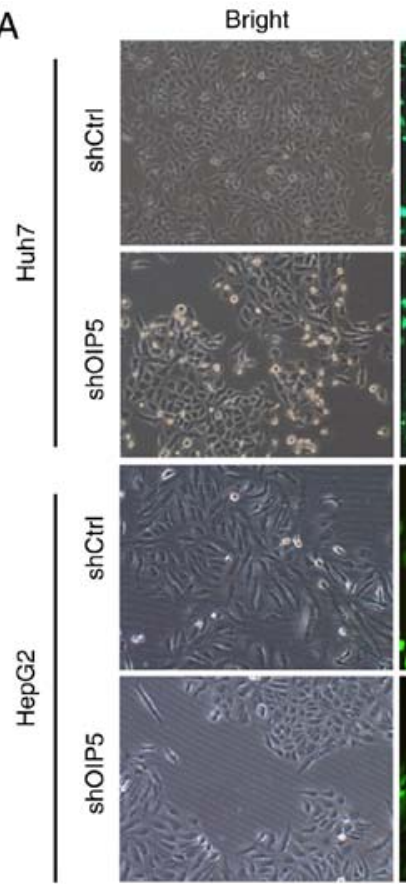

Fluorescent
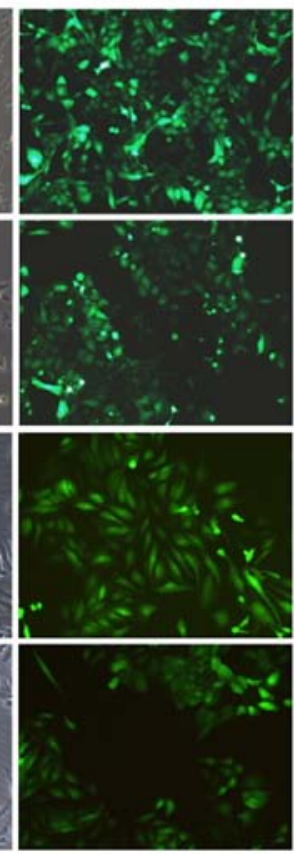

B
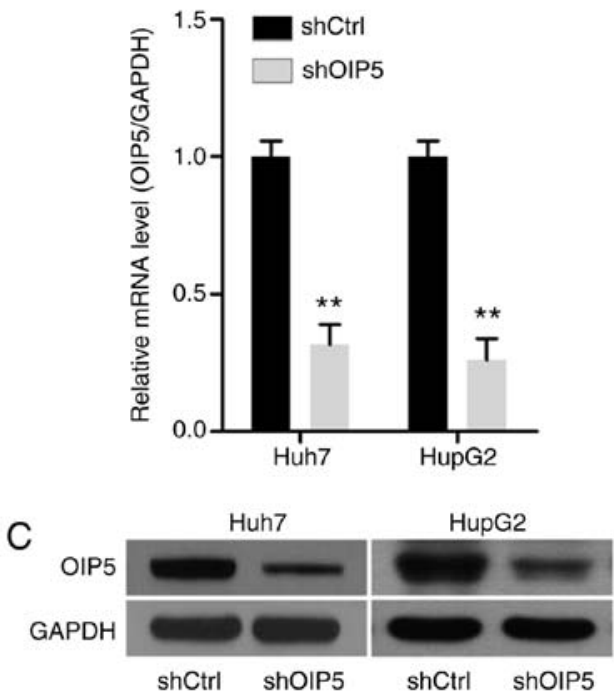

Figure 3. OIP5 expression in both in Huh7 and HepG2 cells following OIP5 knockdown. (A) Transfection efficacy following lentivirus transfection using pGCSIL-shOIP5, and pGCSIL-shCtrl as the control (magnification, x400). (B) OIP5 mRNA expression in Huh7 and HepG2 cells by reverse transcription-quantitative polymerase chain reaction. (C) OIP5 protein expression in Huh7 and HepG2 cells by western blotting. GAPDH was used as the internal control. ${ }^{* *} \mathrm{P}<0.01$ vs. the pGCSIL-shCtrl group. Ctrl, control; sh, short hairpin; OIP5, Opa interacting protein 5.

A

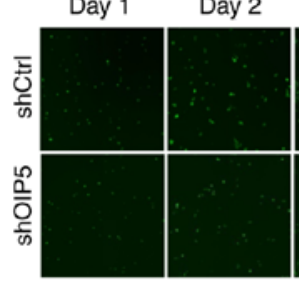

B

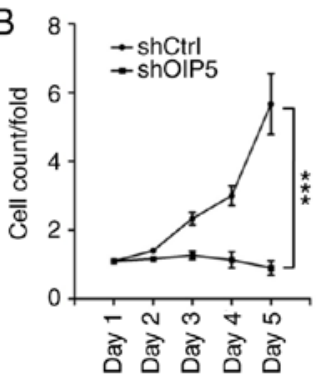

Huh7
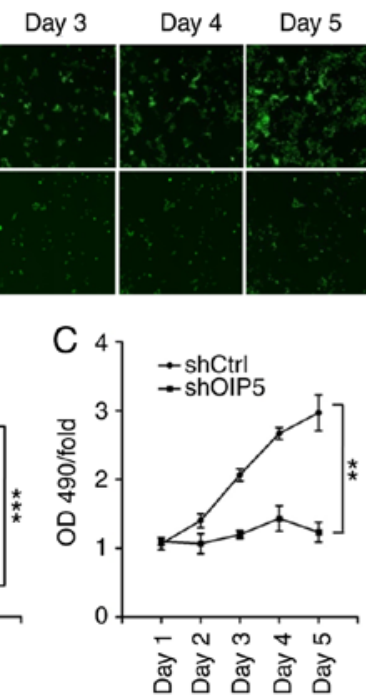

$\mathrm{D}$
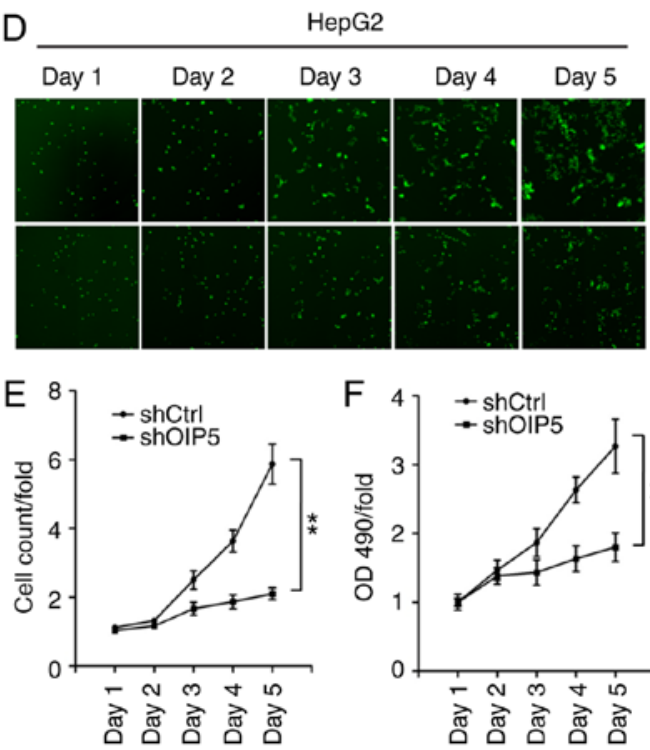

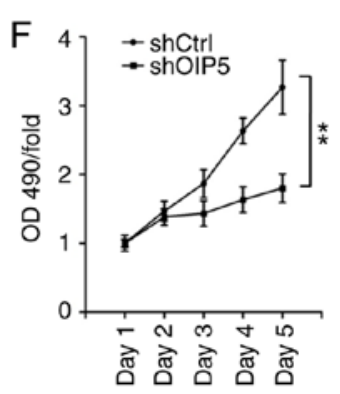

Figure 4. The effect of OIP5 knockdown on Huh7 and HepG2 proliferation. (A) After Huh7 cells was transfected with pGCSIL-shOIP5 or pGCSIL-shCtrl lentivirus, the representative fluorescence microscope images were collected at each day (magnification, x200). (B) The cell counts of Huh7 were measured using an automated cell counter at each day post-infection (pGCSIL-shCtrl vs. pGCSIL-shOIP5 at day 5; ${ }^{* * *} \mathrm{P}<0.001$ ). (C) The proliferation of Huh7 cells was measured with an MTT assay at each day post-infection (pGCSIL-shCtrl vs. pGCSIL-shOIP5 at day 5; ${ }^{* *} \mathrm{P}<0.01$ ). (D) After HepG2 cells was transfected with pGCSIL-shOIP5 or pGCSIL-shCtrl lentivirus, the representative fluorescence microscope images were collected at each day (magnification, x200). (E) The cell counts of HepG2 were measured using an automated cell counter at each day post-infection (pGCSIL-shCtrl vs. pGCSIL-shOIP5 at day 5; ${ }^{* * *} \mathrm{P}<0.01$ ). (F) The proliferation of HepG2 cells was measured with an MTT assay at each day post-infection (pGCSIL-shCtrl vs. pGCSIL-shOIP5 at day 5; * P $<0.01$ ). Ctrl, control; sh, short hairpin; OIP5, Opa interacting protein 5; OD, optical density.

in vivo, Huh7 cells transfected with pGCSIL-shCtrl (control group) or pGCSIL-shOIP5 lentiviruses were transplanted into BALB/c nude mice. Control cells formed tumors in 22 days after implantation, while Huh7 cells transfected with pGCSIL-shOIP5 lentivirus failed to proliferate by 22 days after implantation. As depicted in Fig. 10A and B, shOIP5 treatment significantly reduced tumor size and weight, compared with the control group. The bioluminescence images were observed and analyzed in those nude mice at 4 weeks after Huh7 cells implantation. It was determined that the bioluminescent tumor xenografts exhibited a reduced growth rate in the shOIP5 treatment group, compared with the 
A

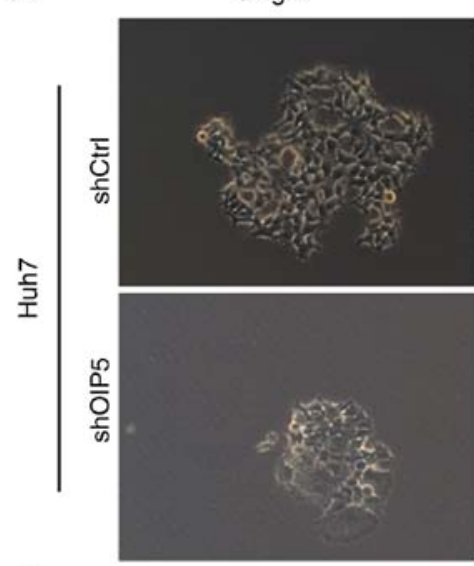

C

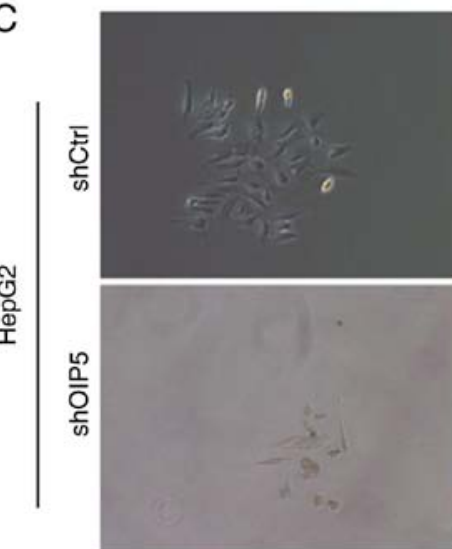

Fluorescent
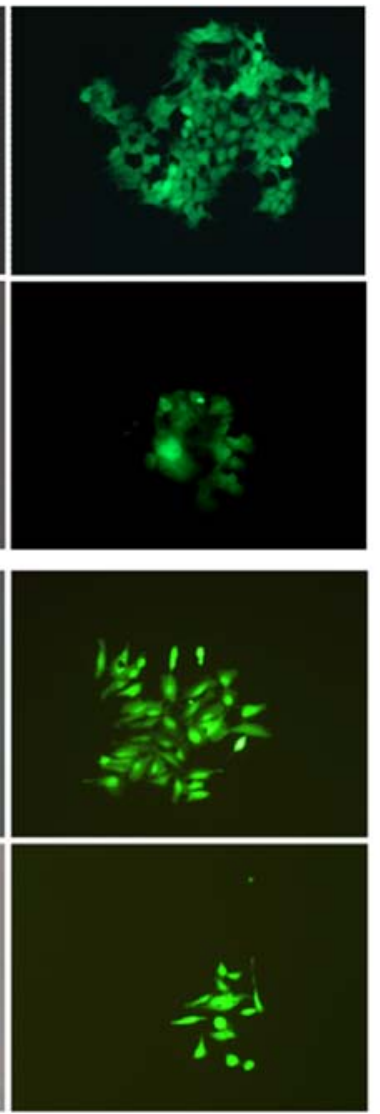

B

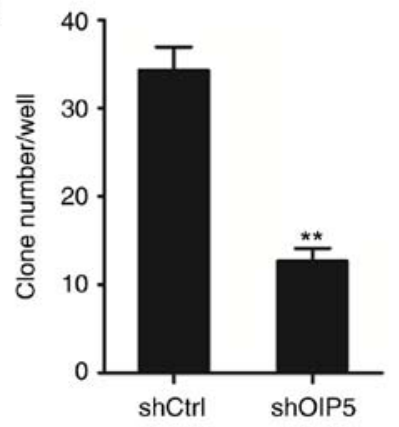

D

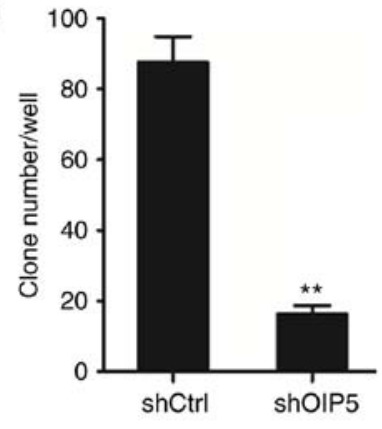

Figure 5. The effect ofOIP5 knockdown on colony formation of Huh7 and HepG2 cells. (A) Photomicrographs of green fluorescent protein-expressing colonies of Huh7 cells in 6-well culture plates (magnification, x400). (B) Mean number of Huh7 cells in each well, "** $<<0.01$ vs. the pGCSIL-shCtrl group. (C) Photomicrographs of green fluorescent protein-expressing colonies of HepG2 cells in 6-well culture plates (magnification, x400). (D) Mean number of HepG2 cells in each well, ${ }^{* *} \mathrm{P}<0.01$ vs. the pGCSIL-shCtrl group. Ctrl, control; sh, short hairpin; OIP5, Opa interacting protein 5.

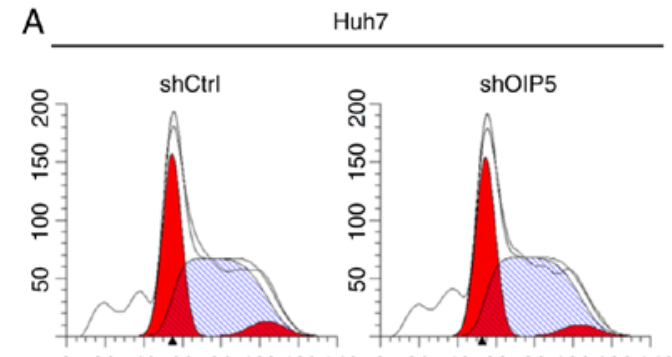

020406080100120140020406080100120140

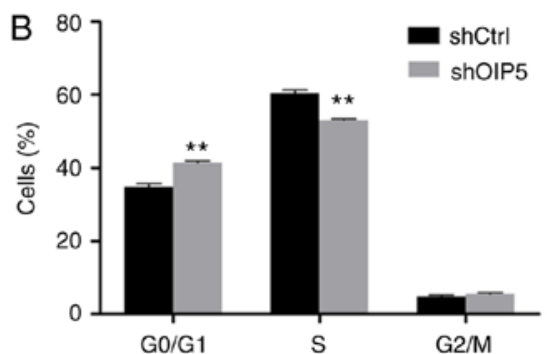

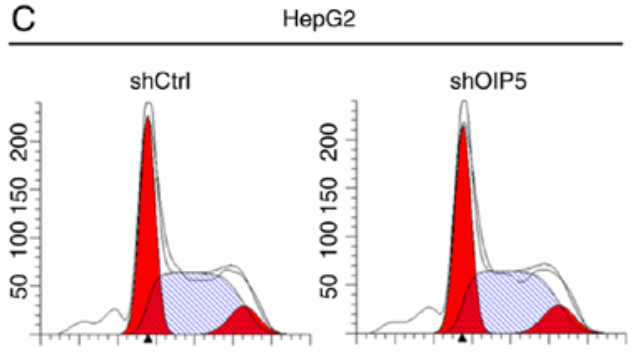

020406080100120140020406080100120140

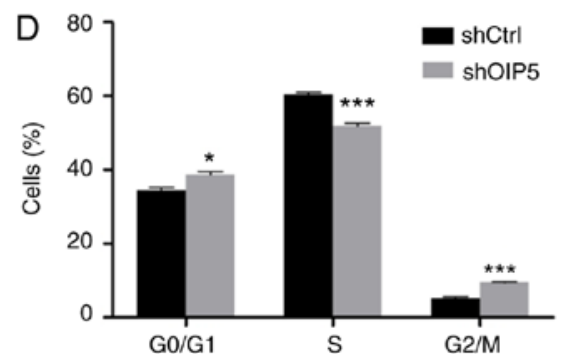

Figure 6. The effect of OIP5 knockdown on the cell cycle of Huh7 and HepG2 cells. (A) Cell cycle analysis of Huh7 cells by flow cytometry. (B) Different cell cycle phases percentages of Huh7 cells. (C) Cell cycle analysis of HepG2 cells by flow cytometry. (D) Different cell cycle phases percentages of HepG2 cells. ${ }^{*} \mathrm{P}<0.05,{ }^{* *} \mathrm{P}<0.01$ and ${ }^{* * * *} \mathrm{P}<0.001$ vs. the pGCSIL-shCtrl group. Ctrl, control; sh, short hairpin; OIP5, Opa interacting protein 5.

control mice (Fig. 10C). Thus, these data indicated that OIP5 knockdown could have an inhibitory effect on liver cancer cell growth and tumorigenicity, suggesting a potential therapeutic approach against liver cancer in which OIP5 is overexpressed. 

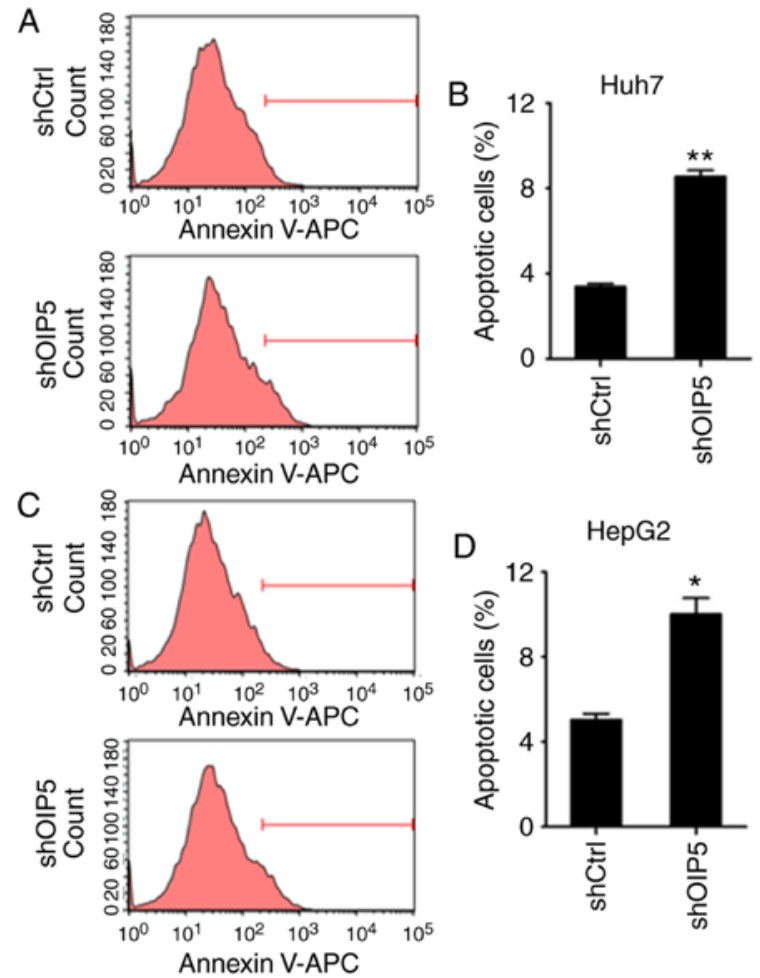

Figure 7. The effects of OIP5 knockdown on cell apoptosis. (A) Annexin V staining and flow cytometry were used to detectthe apoptosis of Huh7 cells (B) Apoptosis was significantly increased in Huh7 cells transfected with pGCSIL-shOIP5, compared with the negative control. (C) Annexin V staining and flow cytometry were used to detect the apoptosis of HepG2 cells. (D) Apoptosis was significantly increased in HepG2 cells transfected with pGCSIL-shOIP5, compared with the negative control. ${ }^{*} \mathrm{P}<0.05$ and ${ }^{* *} \mathrm{P}<0.01$ vs. the pGCSIL-shCtrl group. Ctrl, control; sh, short hairpin; OIP5, Opa interacting protein 5.

A

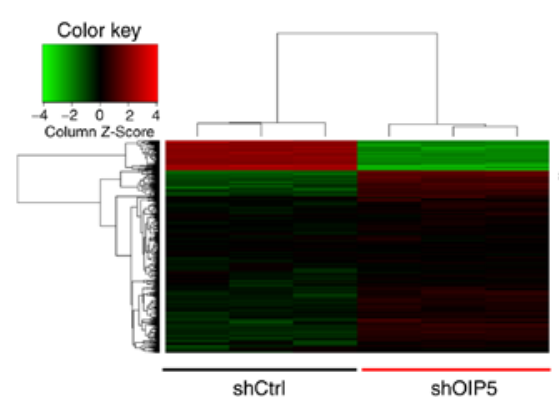

$\mathrm{B}$

\begin{tabular}{c|l|c}
\hline ID & \multicolumn{1}{|c}{ Top diseases and functions } & Score \\
\hline 1 & RNA post-transcriptional modification, cancer, organismal injury and abnormalities & 51 \\
2 & Cell cycle, cancer, connective tissue disorders & 42 \\
3 & DNA replication, recombination, and repair, molecular transport, gene expression & 39 \\
4 & Post-translational modification, endocrine system disorders, gastrointestinal disease & 39 \\
5 & Cellular assembly and organization, cellular function and maintenance, molecular transport & 37 \\
6 & Cell cycle, cell morphology, cellular function and maintenance & 37 \\
7 & RNA post-transcriptional modification, cell morphology, cellular assembly and organization & 37 \\
8 & Drug metabolism, small molecule biochemistry, dermatological diseases and conditions & 33 \\
9 & Lipid metabolism, molecular transport, small molecule biochemistry & 29 \\
10 & Cellular assembly and organization, cellular function and maintenance, cell morphology & 29 \\
\hline
\end{tabular}

Figure 8. IPA summary of DEGs derived from Affymatrix human GeneChip PrimeView containing 20,000 genes. (A) Heatmap of DEGs derived from the microarray. (B) Top 10 networks with their respective scores obtained using IPA. (C) The highest rated network (RNA Post-Transcriptional Modification, Cancer, Organismal Injury and Abnormalities) in IPA. Downregulated genes are depicted in green, whereas upregulated genes are depicted in red. DEGs, differentially-expressed genes; Ctrl, control; sh, short hairpin; OIP5, Opa interacting protein 5. 
A

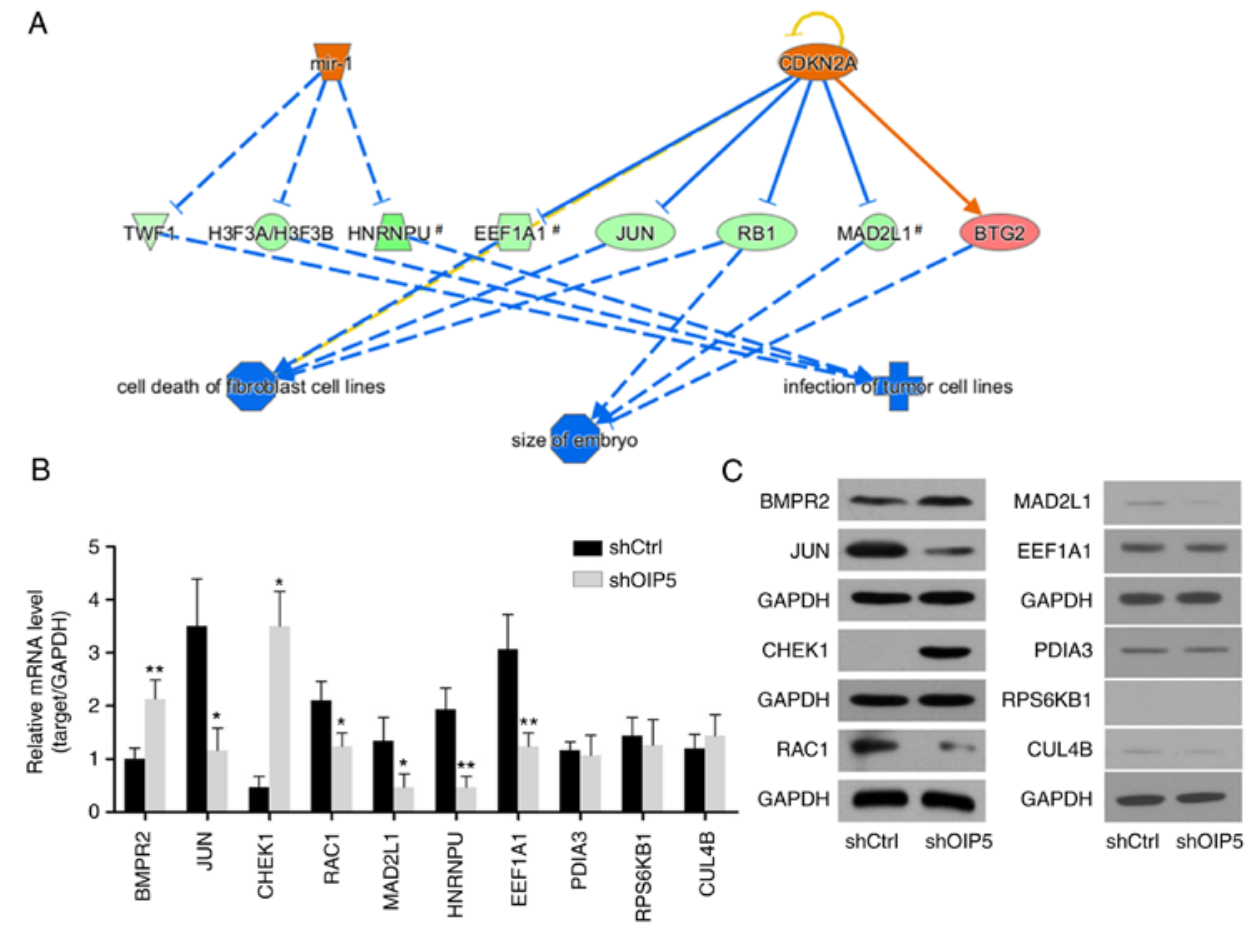

Figure 9. The effect of OIP5 knockdown on downstream genes. (A) Analysis of downstream genes of OIP5 using IPA analysis. (B) RT-qPCR was used to determine the changes in the expression of OIP5 downstream genes in Huh7 cells at $72 \mathrm{~h}$ following pGCSIL-shOIP5 transfection. Samples were normalized to GAPDH mRNA expression. RT-qPCR results are indicated as mean \pm standard deviation of three independent experiments performed in triplicate. GAPDH protein was used as the internal control. ${ }^{*} \mathrm{P}<0.05$ and ${ }^{* *} \mathrm{P}<0.01$ vs. pGCSIL-shCtrl-transfected cells. (C) The expression of OIP5 downstream proteins were analyzed by western blot analysis in Huh7 cells transfected with pGCSIL-shOIP5 lentivirus. ", target genes with a Z-score >3.0; RT-qPCR, reverse transcription-quantitative polymerase chain reaction; Ctrl, control; sh, short hairpin; OIP5, Opa interacting protein 5; mir-1, microRNA1; CDKN2A, cyclin dependent kinase inhibitor 2A; TWF1, twinfilin actin binding protein 1; H3F3A, H3 histone family member 3A; HNRNPU, heterogeneous nuclear ribonucleoprotein U; EEF1A1, eukaryotic translation elongation factor 1 $\alpha 1$; RB1, retinoblastoma 1; MAD2L1, mitotic arrest deficient 2 like 1; BTG2, B-cell translation gene 2; BMPR2, bone morphogenetic protein receptor type 2; CHEK1, checkpoint kinase 1; RAC1, Rac family small GTPase 1; PDIA3, protein disulfide isomerase family A member 3; RPS6KB1, ribosomal protein S6 kinase B1; CUL4B, cullin 4B.

A

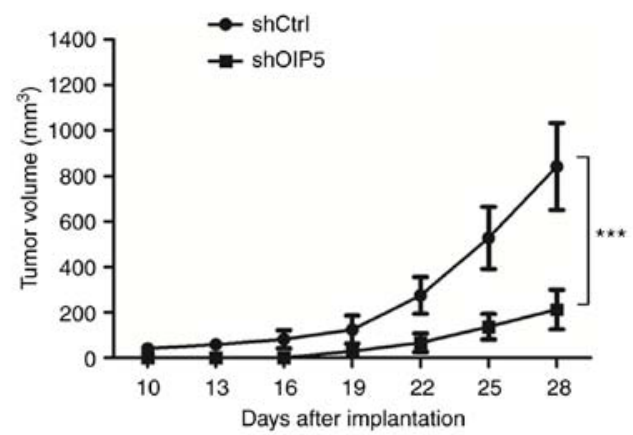

C

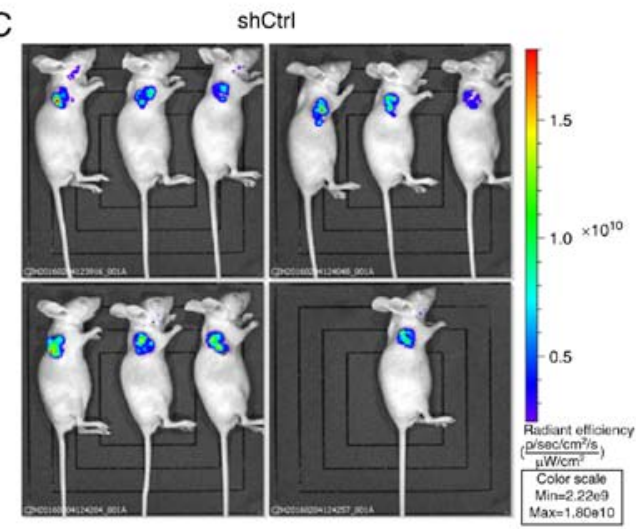

B

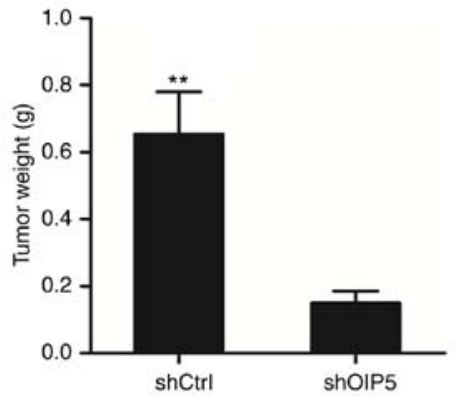

shOIP5

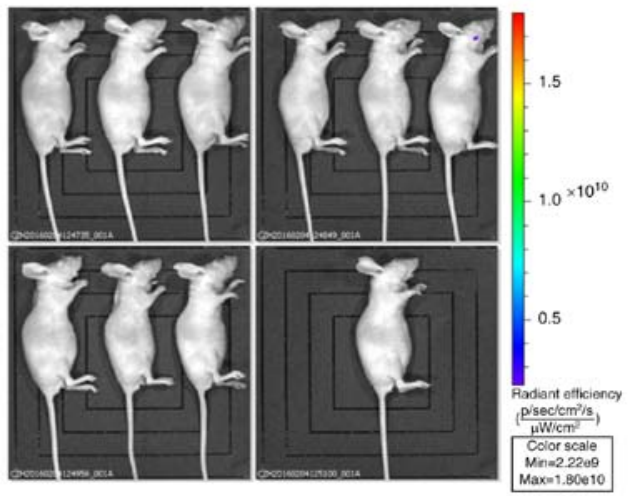

Figure 10. OIP5 knockdown inhibits tumorigenicity of hepatocellular carcinoma cells in vivo. BALB/c nude mice were subcutaneously injected with Huh7 cells transfected with pGCSIL-shCtrl or pGCSIL-shOIP5 lentivirus. (A) Tumor volumes were measured on the indicated days (shCtrl vs. shOIP5 group, ${ }^{* * * *} \mathrm{P}<0.001$ ). (B) Tumor weight was measured at 4 week following injection (shCtrl vs. shOIP5 group, $\left.{ }^{* *} \mathrm{P}<0.01\right)$. (C) Representative bioluminescent imaging of Huh7 cells implanted at 4 weeks after injection, $\mathrm{n}=10$. Ctrl, control; sh, short hairpin; OIP5, Opa interacting protein 5. 


\section{Discussion}

Despite rapid progress in surgical techniques, which are the primary therapies for liver cancer, combined with adjuvant chemotherapy or radiotherapy, patients with liver cancer frequently relapse following liver resection (3). In order to prevent recurrence and treat, for patients who cannot be surgically treated or cannot tolerate radiotherapy and chemotherapy, it is urgent to clarify the mechanism of liver cancer progression to develop novel therapeutic targets highly specific to malignant cells, and have minimal or no risk of adverse effects.

OIP5 is necessary for the recruitment of centromere protein A through the mediator Holiday junction recognition protein $(8,9,26)$. Human OIP5 protein has been first identified using the yeast two-hybrid system (27). The OIP5 protein sequence in human epithelial cells is the same as that of human testis protein (27). As previously reported, the gene is conserved in genome of chimpanzee, Rhesus monkey, cow, dog, chicken and mouse (27).

OIP5 belongs to CTAs, and it is immunogenic, highly specific to cancer and is rarely expressed in the majority of normal tissues; however, it is frequently presented in various cancer types, including lung, breast and esophageal cancer (28). Those characteristics make CTAs promising candidates for cancer immunotherapy (28). CTAs are divided into two subclasses according to the chromosomal localization of their coding genes, which are chromosome X-encoded CTAs and autosomal-encoded CTAs (28). OIP5 is an autosomal-encoded CTA (27). A number of papers have reported that CTAs commonly act as oncogenes involved in tumor progression $(29,30)$. OY-YES-1, a CTAs homolog of human OIP5, is overexpressed in $\mathrm{HCC}$ and its inhibition weakens malignant behaviors of liver cancer cells, including cell growth, cell apoptosis, cell migration and cell metastasis, and then results in cell cycle arrest by regulating caspase-3, matrix metallopeptidase 2 (MMP2), MMP9 and reducing cyclic E expression (30).

OIP5 aberrant expression is common in various types of cancer, including glioblastoma (31), bladder cancer $(32,33)$, acute myeloid leukemia (14), lung, esophageal (15) and breast cancer $(34,35)$, clear cell renal cell carcinoma (11), gastric and colorectal cancer $(12,13)$, and HCC (16). Additionally, He et al (32) reported that the expression of OIP5 was markedly positively associated with sex, tumor size, high-grade tumor and $\mathrm{T}$ classification. Compared with the patients with low OIP5 expression, patients with high OIP5 expression had reduced survival time. In lung and esophageal carcinogenesis, increased expression of OIP5 predicts a reduced patients' overall survival time (15). OIP5 expression is also considered to be positively associated with lymphatic metastasis in esophageal carcinoma (15). As reported by Gong et al (11), the upregulation of OIP5 in patients with clear cell renal cell carcinoma was positively associated with the Fuhrman grade, T classification, $\mathrm{N}$ classification and clinical stage, therefore patients with increased expression of OIP5 exhibited a reduced survival rate. The present data demonstrated that OIP5 is also highly expressed in liver cancer tissues, based on bioinformatics and IHC staining, and patients with liver cancer with a high expression of OIP5 exhibited a markedly decreased overall survival rate, compared with those with low OIP5 expression.
OIP5 is involved in the cell progression of a number of cancer types, including bladder, lung and esophageal cancer, due to its action on cell proliferation, inhibition of cell apoptosis and arrest of the cell cycle $(15,32,33)$. Silencing of OIP5 expression suppressed the colony-forming ability and inhibited tumor cell growth in bladder cancer (32). In lung cancer, esophageal cancer and clear cell renal cell carcinoma, OIP5 down regulation notably depresses cell survival and the colony-forming ability, while restoration of OIP5 expression stimulates cell growth $(11,15)$. Silencing OIP5 expression also inhibits proliferation of gastric and colorectal cancer cells in vitro (12). Furthermore, OIP5 is overexpressed in obese adipose tissues, where it promotes pre- and mature-adipocytes proliferation and causes the occurrence of fatty hyperplasia (36). In the present study, it was identified that OIP5 knockdown inhibited cell proliferation, reduced colony formation and also arrested the cell cycle at the $\mathrm{G}_{0} / \mathrm{G}_{1}$ or $\mathrm{G}_{2} / \mathrm{M}$ phases in liver cancer cells. Furthermore, OIP5 knockdown promoted the apoptosis of those cells. It was considered that cell apoptosis as an important physiological process is associated with the formation of a variety of tumor types $(34,37)$. Thus, the aforementioned results indicated that OIP5 had important roles in the formation of liver cancer.

In order to identify the molecular mechanisms of OIP5-mediated liver cancer progression, the expression profiles of 20,000 genes following OIP5 knockdown in Huh7 cells was determined. OIP5 knockdown in Huh7 cells resulted in the deregulation of 628 genes, 87 of which were upregulated while the remaining 541 were downregulated. Enriched pathways were determined using KEGG and IPA, and it was identified that those differentiated genes were primarily involved in RNA post-transcriptional modification and cell proliferation. Expression data integration at the mRNA and protein levels demonstrated that OIP5 knockdown decreased the expression levels of RAC1. As a member of the Rho family of small GTPases, RAC1 serves a major role in the reactive oxygen species (ROS)-producing NADPH oxidases, which are involved in ROS-dependent signaling (38-40). The present results indicated that OIP5 silencing may be involved in ROS production, which resulted in liver cancer cell apoptosis.

In conclusion, the present results demonstrated the OIP5 involvement in the progression of liver cancer via BMPR2/JUN/CHEK1/RAC1 dysregulation, providing a potential biomarker in liver cancer diagnosis and targeted therapy.

\section{Acknowledgements}

Not applicable.

\section{Funding}

The present study was supported by the National Natural Science Foundation of China (grant no. 81770591), the Key Medical Talents Fund of Jiangsu Province (grant no.ZDRCA2016007) and the Gilead Sciences Research Scholars Program in Liver Disease-Asia, and Medjaden Academy \& Research Foundation for Young Scientists (grant no. MJR20160021). 


\section{Availability of data and materials}

All data generated or analyzed supporting conclusions are included in this published article.

\section{Authors' contributions}

YL, JL, GL and CZ conceived and designed the experiments. YL, FX, WL, PH and RX performed the experiments. YL, $\mathrm{FX}, \mathrm{WL}$ and $\mathrm{CZ}$ conducted the statistical analysis. $\mathrm{YL}$ and $\mathrm{CZ}$ drafted the manuscript. YL, JL, PH, RX, GL and CZ drafted the manuscript. All authors read and approved the manuscript and agree to be accountable for all aspects of the research in ensuring that the accuracy or integrity of any part of the work are appropriately investigated and resolved.

\section{Ethics approval and consent to participate}

The present study was performed with the approval of the Ethics Committee of the First Affiliated Hospital of Nanjing Medical University (approval no. 2006-SRFA-054; Nanjing, China). Written informed consent was obtained from all patients. All of the animal experiments were approved by the Ethics Committee of the Institutional Review Board of the Nanjing Medical University on Animal Experiments (Nanjing, China).

\section{Patient consent for publication}

Written informed consent was obtained from all of the patients included in the study.

\section{Competing interests}

The authors declare that they have no competing interests.

\section{References}

1. Bray F, Ferlay J, Soerjomataram I, Siegel RL, Torre LA and Jemal A: Global cancer statistics 2018: GLOBOCAN estimates of incidence and mortality worldwide for 36 cancers in 185 countries. CA Cancer J Clin 68: 394-424, 2018.

2. Siegel RL, Miller KD and Jemal A: Cancer statistics, 2017. CA Cancer J Clin 67: 7-30, 2017.

3. Heimbach JK, Kulik LM, Finn RS, Sirlin CB, Abecassis MM, Roberts LR, Zhu AX, Murad MH and Marrero JA: AASLD guidelines for the treatment of hepatocellular carcinoma. Hepatology 67: 358-380, 2018.

4. Roayaie S, Obeidat K, Sposito C, Mariani L, Bhoori S, Pellegrinelli A, Labow D, LIovet JM, Schwartz M and Mazzaferro V: Resection of hepatocellular cancer $\leq 2 \mathrm{~cm}$ : Results from two Western centers. Hepatology 57: 1426-1435, 2013.

5. Chun JM, Kwon HJ, Sohn J, Kim SG, Park JY, Bae HI, Yun YK and Hwang YJ: Prognostic factors after early recurrence in patients who underwent curative resection for hepatocellular carcinoma. J Surg Oncol 103: 148-151, 2011.

6. Zhang Y, Li K, Ying Y, Chen B, Hao K, Chen B, Zheng Y, Lyu J, Tong $\mathrm{X}$, Chen $\mathrm{X}$, et al: $\mathrm{C} 21$ steroid-enriched fraction refined from Marsdenia tenacissima inhibits hepatocellular carcinoma through the coordination of Hippo-Yap and PTEN-PI3K/AKT signaling pathways. Oncotarget 8: 110576-110591, 2017.

7. Wang Y, Attar BM, Fuentes HE, Jaiswal P and Tafur AJ: Evaluation of the prognostic value of platelet to lymphocyte ratio in patients with hepatocellular carcinoma. J Gastrointest Oncol 8: 1065-1071, 2017.

8. Afsharpad M, Nowroozi MR, Mobasheri MB, Ayati M, Nekoohesh L, Saffari M,Zendehdel K and Modarressi MH: Cancertestis antigens as new candidate diagnostic biomarkers for transitional cell carcinoma of bladder. Pathol Oncol Res 25: 191-199, 2019.
9. Fujita Y, Hayashi T, Kiyomitsu T, Toyoda Y, Kokubu A, Obuse C and Yanagida M: Priming of centromere for CENP-A recruitment by human hMis18alpha, hMis18beta, and M18BP1. Dev Cell 12: 17-30, 2007.

10. Naetar N, Hutter S, Dorner D, Dechat T, Korbei B, Gotzmann J, Beug $\mathrm{H}$ and Foisner R: LAP2alpha-binding protein LINT-25 is a novel chromatin-associated protein involved in cell cycle exit. J Cell Sci 120: 737-747, 2007.

11. Gong M, Xu Y, Dong W, Guo G, Ni W, Wang Y, Wang Y and An R: Expression of Opa interacting protein 5 (OIP5) is associated with tumor stage and prognosis of clear cell renal cell carcinoma. Acta Histochem 115: 810-815, 2013.

12. Chun HK, Chung KS, Kim HC, Kang JE, Kang MA, Kim JT, Choi EH, Jung KE, Kim MH, Song EY, et al: OIP5 is a highly expressed potential therapeutic target for colorectal and gastric cancers. BMB Rep 43: 349-354, 2010.

13. Nakamura Y, Tanaka F, Nagahara H, Ieta K, Haraguchi N, Mimori K, Sasaki A, Inoue H, Yanaga K and Mori M: Opa interacting protein 5 (OIP5) is a novel cancer-testis specific gene in gastric cancer. Ann Surg Oncol 14: 885-892, 2007.

14. Yazarloo F, Shirkoohi R, Mobasheri M, Emami A and Modarressi M: Expression analysis of four testis-specific genes AURKC, OIP5, PIWIL2 and TAF7L in acute myeloid leukemia: A gender-dependent expression pattern. Med Oncol 30: 368, 2013.

15. Koinuma J, Akiyama H, Fujita M, Hosokawa M, Tsuchiya E, Kondo S, Nakamura Y and Daigo Y: Characterization of an Opa interacting protein 5 involved in lung and esophageal carcinogenesis. Cancer Sci 103: 577-586, 2012.

16. Li H, Zhang J, Lee MJ, Yu GR, Han X and Kim DG: OIP5, a target of miR-15b-5p, regulates hepatocellular carcinoma growth and metastasis through the AKT/mTORC 1 and $\beta$-catenin signaling pathways. Oncotarget 8: 18129-18144, 2017.

17. Deng L, Tang J, Yang H, Cheng C, Lu S, Jiang R and Sun B: MTA1 modulated by miR-30e contributes to epithelial-to-mesenchymal transition in hepatocellular carcinoma through an ErbB2-dependent pathway. Oncogene 36: 3976-3985, 2017.

18. Edmondson HA and Steiner PE: Primary carcinoma of the liver: A study of 100 cases among 48,900 necropsies. Cancer 7: 462-503, 1954.

19. Edge SB and Compton CC: The American Joint Committee on cancer: The 7th edition of the AJCC cancer staging manual and the future of TNM. Ann Surg Oncol 17: 1471-1474, 2010.

20. Szász AM, Lánczky A, Nagy A, Förster S, Hark K, Green JE, Boussioutas A, Busuttil R, Szabó A and Gyorffy B: Cross-validation of survival associated biomarkers in gastric cancer using transcriptomic data of 1,065 patients. Oncotarget 7: 49322-49333, 2016.

21. Lois C, Hong EJ, Pease S, Brown EJ and Baltimore D: Germline transmission and tissue-specific expression of transgenes delivered by lentiviral vectors. Science 295: 868-872, 2002.

22. Pfaffl MW: A new mathematical model for relative quantification in real-time RT-PCR. Nucleic Acids Res 29: e45, 2001.

23. Laemmli UK: Cleavage of structural proteins during the assembly of the head of bacteriophage T4. Nature 227: 680-685, 1970.

24. Liu N, Bi F, Pan Y, Sun L, Xue Y, Shi Y, Yao X, Zheng Y and Fan D: Reversal of the malignant phenotype of gastric cancer cells by inhibition of RhoA expression and activity. Clin Cancer Res 10: 6239-6247, 2004.

25. National research council (US) Committee for the update of the guide for the care and use of laboratory animals: Guide for the care and use of laboratory animals. 8th edition. National Academies Press, Washington, DC, 2011.

26. Kim IS, Lee M, Park JH, Jeon R, Baek SH and Kim KI: $\beta \operatorname{TrCP}$-mediated ubiquitylation regulates protein stability of Mis18 $\beta$ in a cell cycle-dependent manner. Biochem Biophys Res Commun 443: 62-67, 2014.

27. Williams JM, Chen GC, Zhu L and Rest RF: Using the yeast two-hybrid system to identify human epithelial cell proteins that bind gonococcal Opa proteins: Intracellular gonococci bind pyruvate kinase via their Opa proteins and require host pyruvate for growth. Mol Microbiol 27: 171-186, 1998.

28. Gjerstorff MF, Andersen MH and Ditzel HJ: Oncogenic cancer/testis antigens: Prime candidates for immunotherapy. Oncotarget 6: 15772-15787, 2015.

29. Fu J, Luo B, Guo WW, Zhang QM, Shi L, Hu QP, Chen F, Xiao SW and Xie XX: Down-regulation of cancer/testis antigen OY-TES-1 attenuates malignant behaviors of hepatocellular carcinoma cells in vitro. Int J Clin Exp Pathol 8: 7786-7797, 2015. 
30. Fratta E, Coral S, Covre A, Parisi G, Colizzi F, Danielli R, Nicolay HJ, Sigalotti L and Maio M: The biology of cancer testis antigens: Putative function, regulation and therapeutic potential. Mol Oncol 5: 164-182, 2011.

31. Hu GW, Wu L, Kuang W, Chen Y, Zhu XG, Guo H and Lang HL: Knockdown of linc-OIP5 inhibits proliferation and migration of glioma cells through down-regulation of YAP-NOTCH signaling pathway. Gene 610: 24-31, 2017.

32. He X, Hou J, Ping J, Wen D and He J: Opa interacting protein 5 acts as an oncogene in bladder cancer. J Cancer Res Clin Oncol 143: 2221-2233, 2017.

33. He X, Ding X, Wen D, Hou J, Ping J and He J: Exploration of the pathways and interaction network involved in bladder cancer cell line with knockdown of Opa interacting protein 5. Pathol Res Pract 213: 1059-1066, 2017.

34. Li HC, Chen YF, Feng W, Cai H, Mei Y, Jiang YM, Chen T, Xu K and Feng DX: Loss of the Opa interacting protein 5 inhibits breast cancer proliferation through miR-139-5p/NOTCH1 pathway. Gene 603: 1-8, 2017.

35. Mobasheri MB, Shirkoohi R and Modarressi MH: Cancer/Testis OIP5 and TAF7L genes are up-regulated in breast cancer. Asian Pac J Cancer Prev 16: 4623-4628, 2015.
36. Inoue K, Maeda N, Mori T, Sekimoto R, Tsushima Y, Matsuda K, Yamaoka M, Suganami T, Nishizawa H, Ogawa Y, et al: Possible involvement of Opa-interacting protein 5 in adipose proliferation and obesity. PLoS One 9: e87661, 2014.

37. Kim TW, Lee SJ, Park YJ, Park SY, Oh BM, Park YS, Kim BY, Lee YH, Cho HJ, Yoon SR, et al: Opa-interacting protein 5 modulates docetaxel-induced cell death via regulation of mitophagy in gastric cancer. Tumour Biol 39: 1010428317733985, 2017.

38. Schnelzer A, Prechtel D, Knaus U, Dehne K, Gerhard M, Graeff H, Harbeck N, Schmitt M and Lengyel E: Racl in human breast cancer: Overexpression, mutation analysis, and characterization of a new isoform, Raclb. Oncogene 19: 3013-3020, 2000.

39. Hordijk PL: Regulation of NADPH oxidases: The role of Rac proteins. Circ Res 98: 453-462, 2006.

40. Melzer C, von der Ohe J, Hass $\mathrm{R}$ and Ungefroren $\mathrm{H}$ : TGF- $\beta$-dependent growth arrest and cell migration in benign and malignant breast epithelial cells are antagonistically controlled by Rac1 and Rac1b. Int J Mol Sci 18: pii: E1574, 2017.

This work is licensed under a Creative Commons Attribution-NonCommercial 4.0 International (CC BY-NC 4.0) License. 